\title{
Article \\ A Polyimide-Based Flexible Monopole Antenna Fed by a Coplanar Waveguide
}

\author{
Dingyong Cang ${ }^{1}\left(\mathbb{D}\right.$, Zhiliang Wang $^{1,2, *}$ and Huiwen $\mathrm{Qu}^{1}{ }^{1}$ \\ 1 School of Information Science and Technology, Nantong University, Nantong 226019, China; \\ cangdingyong@hotmail.com (D.C.); qhw_xx@hotmail.com (H.Q.) \\ 2 Shanghai Key Laboratory of Multidimensional Information Processing, East China Normal University, \\ Shanghai 200241, China \\ * Correspondence: wangzl@ntu.edu.cn
}

\section{check for}

updates

Citation: Cang, D.; Wang, Z.; Qu, H. A Polyimide-Based Flexible Monopole Antenna Fed by a Coplanar Waveguide. Electronics 2021, 10, 334. https://doi.org/10.3390/ electronics10030334

Academic Editor: Emilio Arnieri

Received: 2 January 2021

Accepted: 28 January 2021

Published: 1 February 2021

Publisher's Note: MDPI stays neutral with regard to jurisdictional claims in published maps and institutional affiliations.

Copyright: (c) 2021 by the authors. Licensee MDPI, Basel, Switzerland. This article is an open access article distributed under the terms and conditions of the Creative Commons Attribution (CC BY) license (https:/ / creativecommons.org/licenses/by/ $4.0 /)$.

\begin{abstract}
A 2.4 GHz flexible monopole antenna fed by a coplanar waveguide (CPW) was presented on polyimide (PI) as the dielectric substrate, which was fabricated by in situ self-metallization. The technology does not depend on expensive equipment or complex experimental environments, including hydrolysis, ion exchange, and reduction reaction. The measurement results show that the resonance frequency of the proposed antenna is $2.28 \mathrm{GHz}$, the bandwidth is $2.06-2.74 \mathrm{GHz}$, and the relative bandwidth is $28.33 \%$ under the flat state. The bending and folding test was also carried out. Whether it was flat, bent, or folded, the measured results met the requirements of the antenna. A fatigue test was carried out to illustrate that the prepared film has high mechanical flexibility, which expands the application field of antenna.
\end{abstract}

Keywords: flexible monopole antenna; coplanar waveguide; polyimide; in situ self-metallization

\section{Introduction}

The flexible antennas fed by coplanar waveguides (CPW) have attracted more and more attention for their advantages of convenient integration with other microwave components and easy conforming to the carrier [1-4]. For example, a flexible antenna fed by a CPW, which has the advantages of low profile, simple structure, small size, cheap production, and without vias or lumped element components was designed in ref 1 . In ref 2, flexible flower-shaped CPW-fed antennas for high data wireless applications were proposed. In ref 3, a flexible millimeter-wave (mm-wave) antenna array for fifth generation (5G) wireless networks operating at Ka-band $(26.5-40 \mathrm{GHz})$ was presented. In ref 4, a flexible fractal electromagnetic bandgap (EBG) was fabricated and its performance impact on a wearable CPW antenna in the frequency range $20-40 \mathrm{GHz}$ was evaluated. The research on the performance of flexible CPW antennas under flat and bending conditions has achieved great results; however, the antennas usually need to not only be bent but also be folded in practical applications. Therefore, how to adopt a folding antenna without reducing its performance is one focus of the flexible CPW antenna design.

On the other hand, increasing attention has been paid to flexible substrates of CPW antenna because of the increasing demand for antennas that can be mounted easily on devices having non-flat surfaces [5-7]. In ref 5, an M-shaped printed monopole antenna based on a polyimide (PI) substrate was reported. In ref 6, a compact ultrawideband (UWB) antenna printed on a PI substrate was reported. In ref 7, a flexible, ultra-low profile, and compact dual band antenna was reported, which was inkjet-printed on a PI substrate and fed by coplanar waveguide. PI has a trend to be chosen as the substrate because it has more advantages in terms of cost performance, and it exhibits a good balance of physical, chemical, and electrical properties [5-15]. Major manufacturing technologies for CPW antennas on PI films include lithography [16] and printing [5-7,17,18], which rely on expensive equipment or strict experimental environment requirements [5-7,19-22], 
and the metal layers fabricated by these proposed methods easily crack and shed [23,24]. The method of in situ self-metallization can resolve these problems mentioned above [24,25]. Highly reflective and conductive metallized polyimide films [24,25], inserting electrode [26], copper electrode [27], and patterned copper circuit [28] have been successfully prepared by in situ self-metallization techniques, and the above work lays a good foundation for the fabrication of the flexible antenna.

In this work, a flexible monopole antenna fed by coplanar waveguide was fabricated on a PI substrate by in situ self-metallization. The CPW feed was selected because it has the advantages of low profile and simple structure, and both the ground planes and the radiators are etched on the same side of the PI substrates, which simplified the fabrication process of the antenna. The measurement results showed that the resonance frequency of the proposed antenna was $2.28 \mathrm{GHz}$, the bandwidth was $2.06-2.74 \mathrm{GHz}$, and the relative bandwidth was $28.33 \%$ under the flat state. The radiation characteristics of the flexible monopole antenna under different bending and folding states were tested. Whether it was flat, bent, or folded, the measured results met the requirements of the antenna. Fatigue tests were carried out to illustrate that the prepared film has a high mechanical flexibility. The proposed flexible monopole antenna can be suitable for WLAN/WiMax systems.

\section{Materials and Methods}

\subsection{Design}

The proposed flexible monopole antenna is designed to work in the industrial, scientific, and medical (ISM) $2.4 \mathrm{GHz}$ band [29-31]. Figure 1 shows the geometrical shape and size of the flexible monopole antenna. The yellow part is the PI substrate, and the flexible antenna is fabricated on it. The gray part is silver layer, which was obtained by in situ self-metallization. PI was chosen as the substrate for the antenna because it shows good physical, chemical, and electrical properties with a dielectric constant of 3.5 and a loss tangent of 0.008 . Matching at the chosen bands, the flexible monopole antenna consisted of a radiating element and coplanar waveguide having rectangular ground planes. In order to further miniaturize the antenna, an inverted $\mathrm{L}$ to the right was selected as the radiating element. The CPW feed was selected because of its simple feeding mode, and both the ground planes and the radiators were etched on the same side of the PI substrate. The ground planes and feed line were designed and optimized to adjust the impedance matching and operating bands of the antenna. The length and width of the L-shaped monopole, in addition to the ground plane size, controlled the resonant frequency of the flexible antenna, which was designed to cover the ISM band.

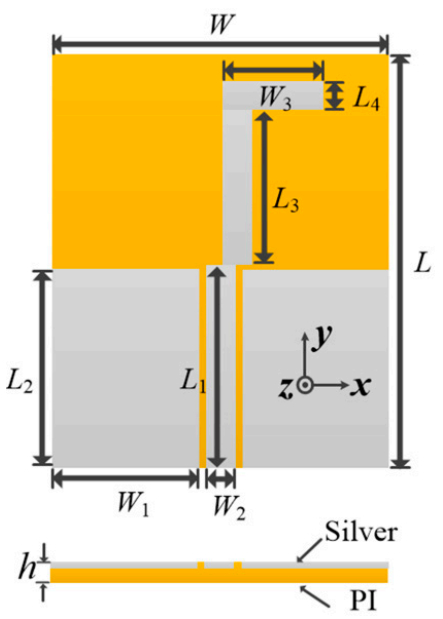

Figure 1. Schematic view of the proposed antenna. 


\subsection{Parametric Analysis}

To clearly demonstrate the characteristics of the proposed flexible antenna, ANSYS HFSS simulation software was used to carry out parametric analysis, including the length $\left(L_{3}\right)$ and width $\left(L_{4}\right)$ of the inverted $L$.

Figure 2a shows the simulated reflection coefficient with length $L_{3}$ varied from 17.8 to $19.8 \mathrm{~mm}$ with $1 \mathrm{~mm}$ steps in the range, which other parameters remained the same. As can be seen from the figure, with the increase in the length of $L_{3}$, the resonant frequency and bandwidth of the antenna gradually moved to the right, which could not meet the design requirements of the flexible antenna.

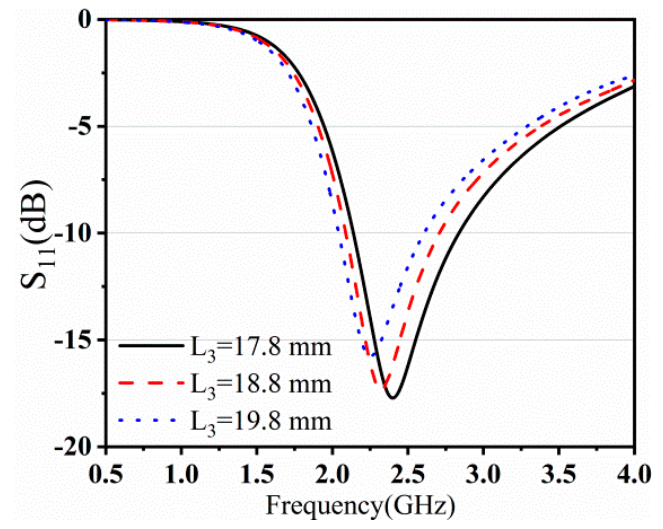

(a)

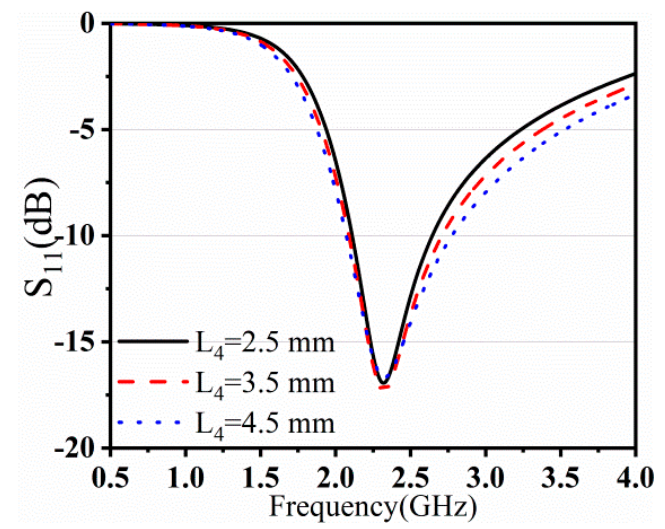

(b)

Figure 2. Simulated reflection coefficient varies with the parameters: (a) $L_{3}$; (b) $L_{4}$.

Figure $2 \mathrm{~b}$ shows the variation of reflection coefficient with respect to the length $L_{4}$ (e.g., $2.5 \mathrm{~mm}, 3.5 \mathrm{~mm}$, and $4.5 \mathrm{~mm}$ ). Other parameters remained fixed. As can be seen from the figure, with the increase in the length of $L_{4}$, the resonant frequency of the antenna remained unchanged and the bandwidth increased slightly. When $L_{4}$ was set at $3.5 \mathrm{~mm}$, the reflection coefficient of the antenna had the maximum value, so $3.5 \mathrm{~mm}$ of $L_{4}$ was the optimal solution.

After a series of simulation optimization, the final antenna size was determined to be: $40.6 \mathrm{~mm} \times 50 \mathrm{~mm} \times 0.075 \mathrm{~mm}$, and specifically as follows: $W=40.6 \mathrm{~mm}, W_{1}=18.3 \mathrm{~mm}$, $W_{2}=3.6 \mathrm{~mm}, W_{3}=12.1 \mathrm{~mm}, L=50 \mathrm{~mm}, L_{1}=24.5 \mathrm{~mm}, L_{2}=24 \mathrm{~mm}, L_{3}=18.8 \mathrm{~mm}$, $L_{4}=3.5 \mathrm{~mm}, h=0.075 \mathrm{~mm}$.

\subsection{Fabrication}

In situ self-metallization technology requires only simple chemical agents, such as $\mathrm{KOH}, \mathrm{AgNO}_{3}, \mathrm{NH}_{3} \cdot \mathrm{H}_{2} \mathrm{O}$ and $\mathrm{H}_{2} \mathrm{O}_{2}$. The method does not rely on expensive equipment or complex experimental environments, including hydrolysis, ion exchange, and reduction reactions. Figure 3 shows the manufacture process of the antenna that was made in five steps.

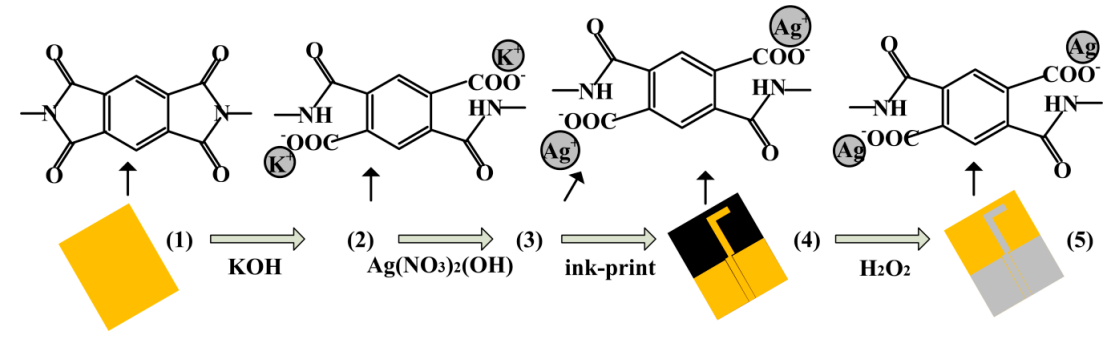

Figure 3. The manufacture process of the antenna. 
Step 1: PI film: The film was cleaned with deionized water to assess whether the film met the standard of antenna preparation;

Step 2: Composite films with $\mathrm{K}^{+}$: One side of the cleaned film was immersed in $4 \mathrm{M}$ $\mathrm{KOH}$ solution for $3 \mathrm{~h}$ to modify the surface of the film to poly (amic acid) (PAA);

Step 3: Composite films with $\mathrm{Ag}^{+}$: The film was immersed in $0.04 \mathrm{M} \mathrm{Ag}\left(\mathrm{NH}_{3}\right)_{2} \mathrm{OH}$ solution for $2 \mathrm{~h}$ to form the silver ion-doped layers;

Step 4: Ink-printed films: The dry film was affixed to the paper and a printer was used to print the area outside the antenna structure on the reaction surface;

Step 5: Silvered PI films: The printed film was immersed in $0.1 \mathrm{M} \mathrm{H}_{2} \mathrm{O}_{2}(30 \%)$ solution for $10 \mathrm{~s}$ to reduce the silver ions.

After these five steps, the films were cleaned to obtain the antenna. The experiment can be conducted at room temperature, and specific steps can be found in the literature $[24,25]$.

\section{Crystal Structures and Morphologies}

The prepared silvered PI film was studied by X-ray diffraction (XRD, Ultima IV). In Figure 4a, the XRD spectra are in good agreement with the data of the standard JCPDS (04-0783), indicating that the surface of the silver-plated PI film is composed of face-centered cubic silver crystal particles.

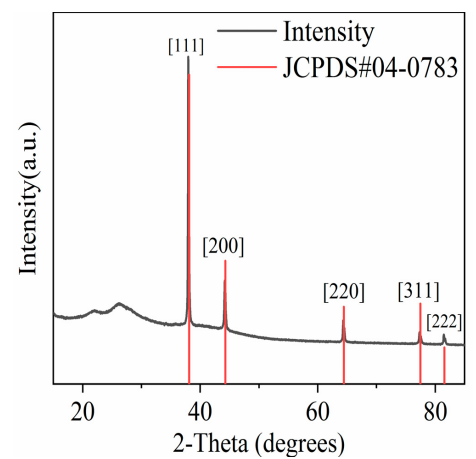

(a)

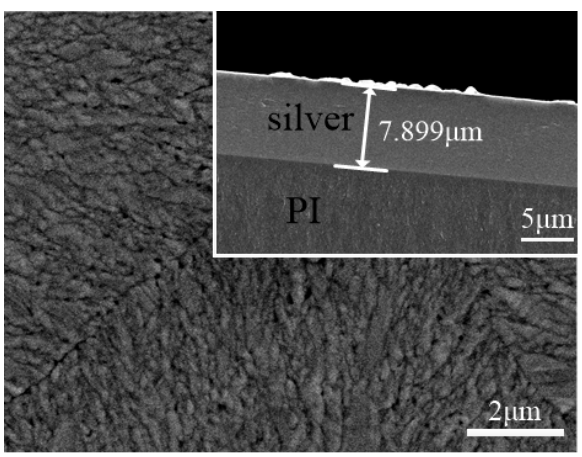

(b)

Figure 4. (a) XRD image. (b) Top and cross-sectional SEM images.

The surface and cross section of the prepared composite film were identified by scanning electron microscope (SEM, JSM-6510). In Figure $4 \mathrm{~b}$, the silver layer is uniformly dense. The insertion diagram in the upper right corner shows that the thickness of the metallized layer formed was about $7.899 \mu \mathrm{m}$, the resistivity of which meets the requirements of antenna radiation according to the literature [25].

\section{Flexibility Study}

\subsection{Simulation}

Figure 5a-c show the diagrams of surface current under the flat, bending, and folding states. As can be seen from these diagrams, when the antenna was bent $(R=40 \mathrm{~mm})$ and folded $\left(\theta=150^{\circ}\right)$, the direction of surface current changed relative to the flat state.

Figure $6 \mathrm{a}-\mathrm{c}$ show the simulated performances of the antenna under the flat, bending, and folding states. In Figure 6a, whether it is flat, bent or folded, the simulated reflection coefficients are similar [32]. Specific performances are listed in Table 1. 


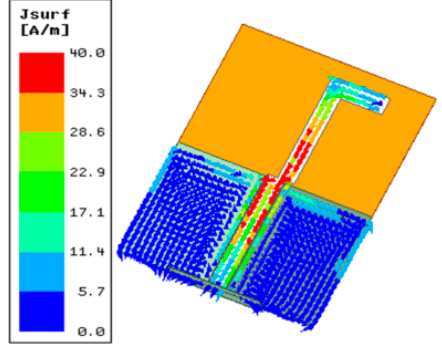

(a)

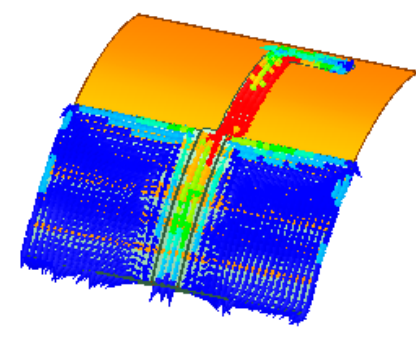

(b)

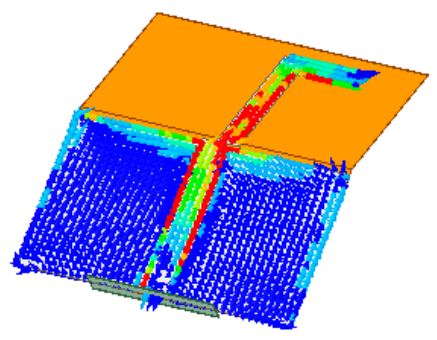

(c)

Figure 5. Diagrams of surface current. (a) Flat. (b) Bent. (c) Folded.

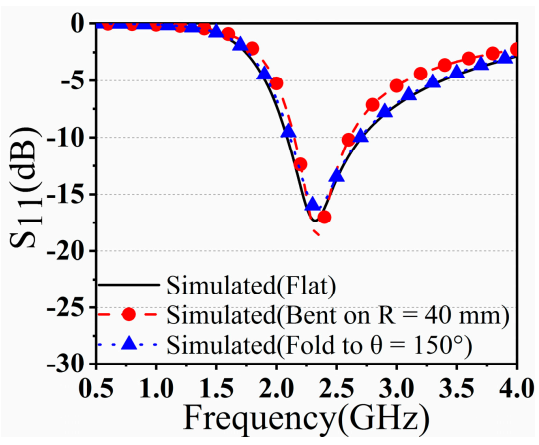

(a)

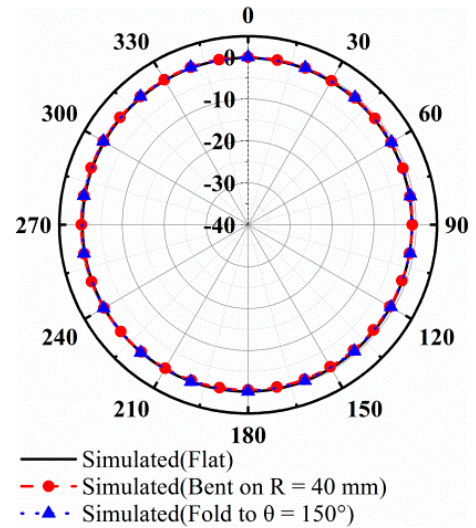

(b)

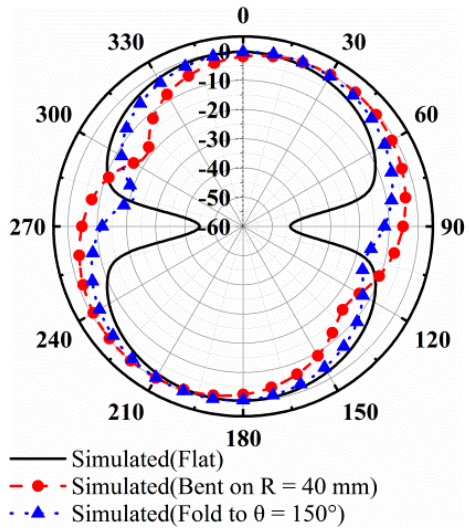

(c)

Figure 6. Simulated performance of the antenna under the flat, bending, and folding states. (a) Reflection coefficients. Radiation patterns: (b) $x-z$ plane; (c) $x-y$ plane.

Table 1. Simulated performance comparison of the antenna under the flat, bending, and folding states.

\begin{tabular}{cccc}
\hline & Resonant Frequency $(\mathbf{G H z})$ & $\mathbf{S}_{\mathbf{1 1}}(\mathbf{d B})$ & Bandwidth $(\mathrm{GHz})$ \\
\hline Flat & 2.32 & -17.35 & $2.10-2.70(25.00 \%)$ \\
$\mathrm{R}=40 \mathrm{~mm}$ & 2.34 & -18.75 & $2.15-2.61(19.33 \%)$ \\
$\theta=150^{\circ}$ & 2.34 & -16.26 & $2.11-2.69(24.16 \%)$ \\
\hline
\end{tabular}

Figure $6 \mathrm{~b}$ shows the simulated radiation patterns in $x-z$ planes, which still have omnidirectional radiation patterns after bending and folding. Figure $6 \mathrm{c}$ shows the simulated radiation patterns in $x-y$ planes, which have obvious changes. The bending and folding lead to changes in the current flow direction of the patch surface, which change the axial direction of the direction graph of $x-y$ planes [33]. 


\subsection{Flat Test}

The fabricated flexible monopole antenna on the PI film is shown in Figure 7a. A small SubMiniature-A (SMA) connector was used to connect the flexible monopole antenna for testing.

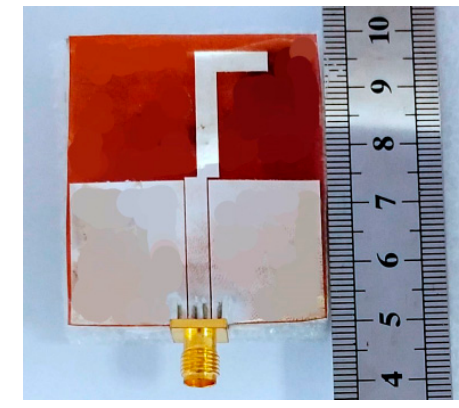

(a)

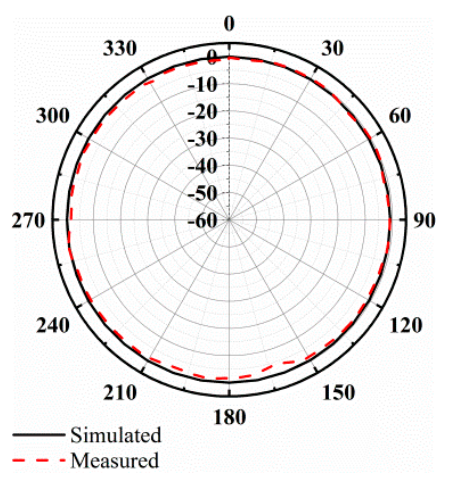

(c)

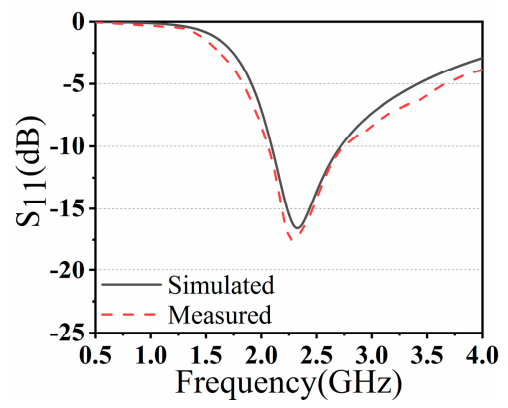

(b)

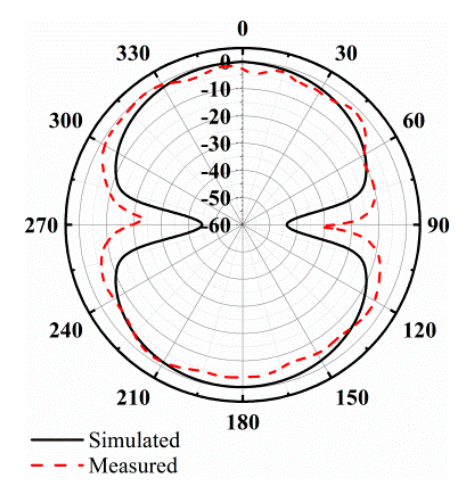

(d)

Figure 7. (a) Photographs of the fabricated prototype. Simulated and measured characteristics under the flat state. (b) Reflection coefficients. Radiation patterns: (c) $x-z$ plane; (d) $x-y$ plane.

To verify the radiation characteristics of the flexible monopole antenna, the reflection coefficients were tested. As shown in Figure $7 \mathrm{~b}$, when the flexible monopole antenna was under the flat state, the measured reflection coefficients were similar to the simulated results. Changes of the performances between simulation and measurement are listed in Table 2.

Table 2. Simulated and measured performance comparison of the antenna under the flat state.

\begin{tabular}{cccc}
\hline & Resonant Frequency $(\mathbf{G H z})$ & $\mathbf{S}_{\mathbf{1 1}}(\mathrm{dB})$ & Bandwidth $(\mathrm{GHz})$ \\
\hline Simulation & 2.32 & -17.35 & $2.10-2.70(25.00 \%)$ \\
Measurement (Flat) & 2.28 & -17.64 & $2.06-2.74(28.33 \%)$ \\
\hline
\end{tabular}

The far-field radiation patterns were measured inside the anechoic chamber. The antenna under test (AUT) was placed on a swivel table and aligned to a horn antenna. Under the flat state, the simulated and measured radiation patterns are shown in Figure $7 \mathrm{c}, \mathrm{d}$. In Figure $7 c$, the radiation patterns in $x-z$ planes have omnidirectional radiation patterns at this frequency $(2.28 \mathrm{GHz})$. Figure $7 \mathrm{~d}$ shows the radiation patterns in $x-y$ planes. The deviation between the measured results and the simulated results are small.

\subsection{Bending Test}

To study the mechanical flexibility of flexible monopole antenna, the reflection coefficients and radiation patterns were tested under different bending states. As shown 
in Figure 8a, the antenna is attached to a curved surface. The small image in the lower right is a schematic of the bending antenna, and $R$ is the bending radius $(R=40 \mathrm{~mm}$ and $R=60 \mathrm{~mm}$ ). As shown in Figure 8b, compared with the flat state, its operating frequency band, resonant frequency, and relative bandwidth are almost invariant.

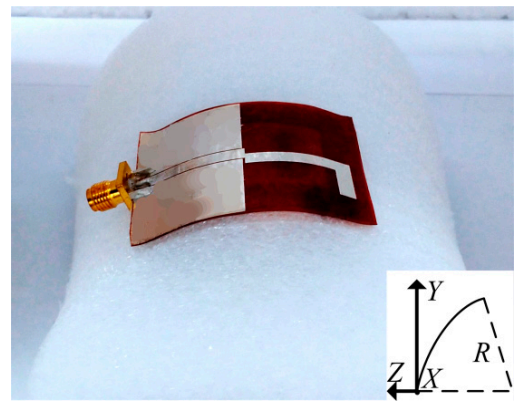

(a)

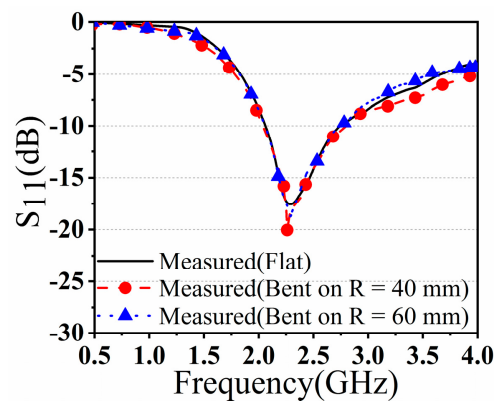

(b)

Figure 8. (a) Photograph. (b) Measured reflection coefficients under the flat and bending states.

Figure 9 shows the far-field radiation patterns of the antenna under different bending states. In Figure $9 \mathrm{a}$, the radiation patterns in $x-z$ planes are shown, which have a great omnidirectional performance. Figure $9 \mathrm{~b}$ shows the radiation patterns in $x-y$ planes. Changes of the $x-y$ planes are obvious under the bending state, which is caused by the current flow direction change on the surface.

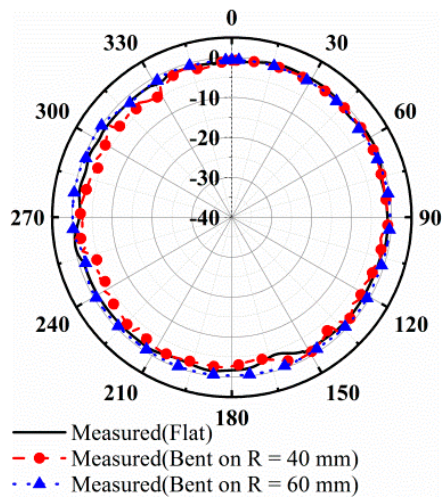

(a)

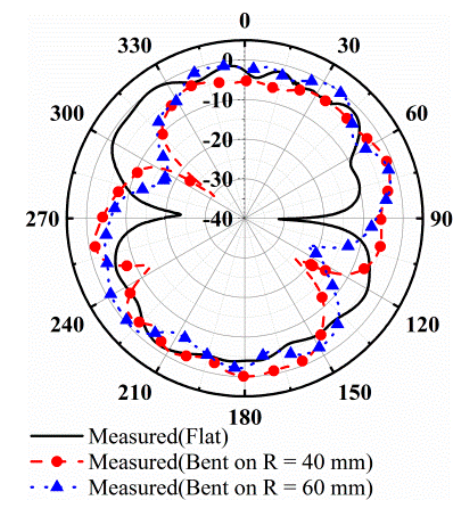

(b)

Figure 9. Measured radiation patterns under the flat and bending states. (a) $x-z$ plane. (b) $x-y$ plane.

\subsection{Folding Test}

Furthermore, the folding effect on the practical reflection coefficients and far-field radiation patterns was also studied. As shown in Figure 10a, the flexible monopole antenna was folded in half to create a crease. The image in the lower right is a schematic of the folding antenna, and $\theta$ is the folding angle $\left(\theta=150^{\circ}\right)$. In Figure $10 \mathrm{~b}$, compared with the flat state, when there was a crease, its operating frequency band, resonant frequency, and relative bandwidth were almost invariant. Table 3 shows the variations of the measured performance of the antenna under flat and folding states. Figure 10c,d show the far-field radiation patterns under the folding state. In Figure 10c, the radiation patterns in $x-z$ planes are shown, which have omnidirectional radiation patterns. Figure 10d shows the radiation patterns in $x-y$ planes. The reason for the changes is the same as the bending state. 


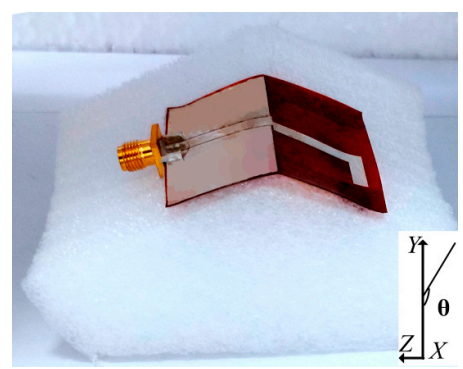

(a)

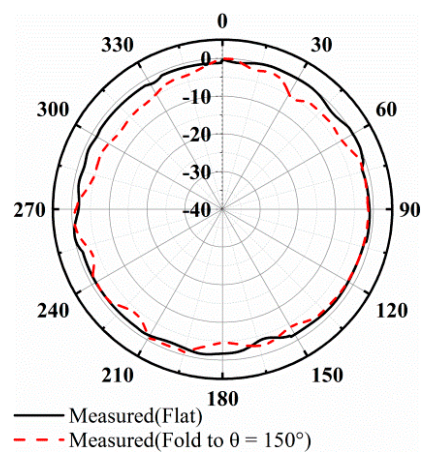

(c)

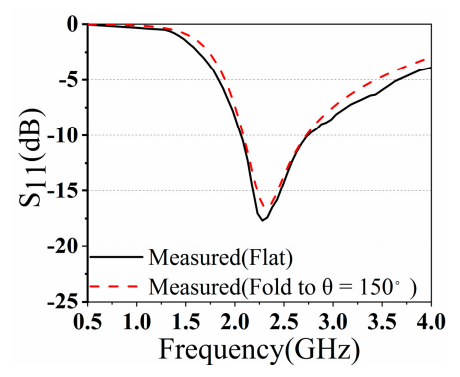

(b)

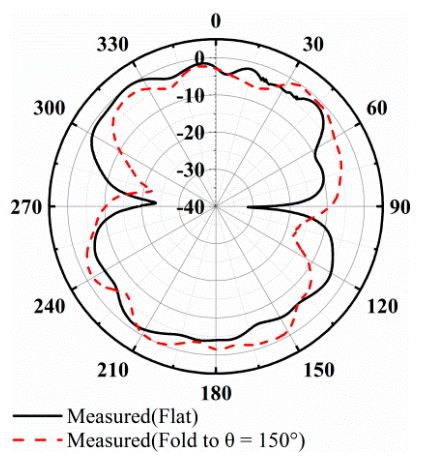

(d)

Figure 10. (a) Photograph. Measured characteristics under the flat and folding states. (b) Reflection coefficients. Radiation patterns: (c) $x-z$ plane; (d) $x-y$ plane.

Table 3. Measured performance comparison of the antenna under the flat and folding states.

\begin{tabular}{cccc}
\hline Angle & Resonant Frequency $(\mathbf{G H z})$ & $\mathbf{S}_{\mathbf{1 1}}(\mathbf{d B})$ & Bandwidth $(\mathbf{G H z})$ \\
\hline Flat $\left(0^{\circ}\right)$ & 2.28 & -17.64 & $2.06-2.74(28.33 \%)$ \\
Fold $\left(150^{\circ}\right)$ & 2.32 & -16.60 & $2.05-2.75(29.16 \%)$ \\
\hline
\end{tabular}

Figure 11 shows the measured gain and efficiency when the flexible monopole antenna was under the flat, bent, and folded states. In Figure 11a, the measured realized gains of the antenna are shown. It can be seen that the realized gains of the antenna have the same trend, which met the performance requirements. When the antenna was flat, the maximum gain achieved was $2.98 \mathrm{dBi}$. In Figure $11 \mathrm{~b}$, when the antenna was flat, bent $(R=40 \mathrm{~mm})$ and folded $\left(\theta=150^{\circ}\right)$, the efficiencies of the flexible monopole antenna were above $80 \%$ in the entire working bandwidth, which had the same trend, and the maximum efficiency achieved was over $90 \%$.

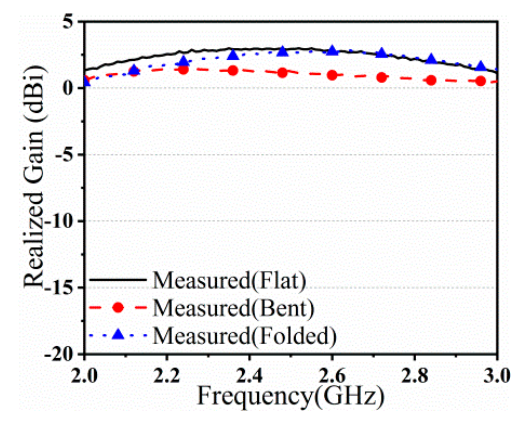

(a)

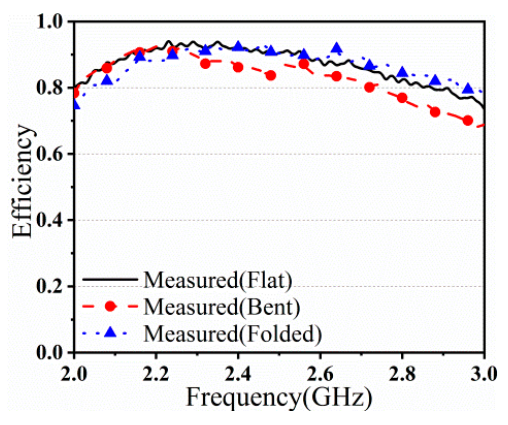

(b)

Figure 11. Measurement of the antenna under the flat, bending, and folding states. (a) Realized Gain. (b) Efficiency. 


\subsection{Fatigue Test}

Finally, fatigue test was also studied. The flexible antenna was folded in half 50 times and fixed on the foam for a period of time. Figure 12 shows the measured performance comparison, which indicates that the performance of the antenna did not changed much from that before. It can be seen that the flexible antenna fabricated by in situ self-metallization had stable chemical and mechanical properties.

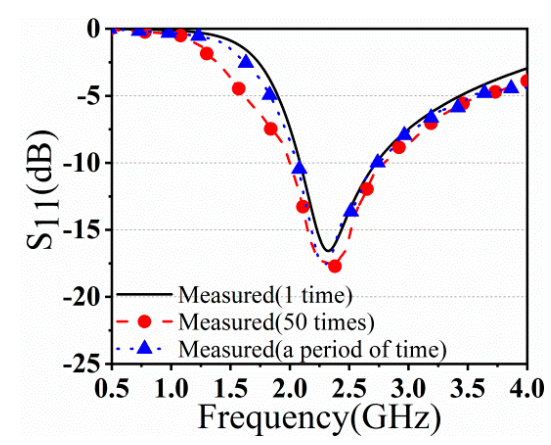

Figure 12. Comparison of measured performance of fatigue tests.

In Figure 13, top and cross-sectional SEM images are shown when the film was folded in half 50 times. In the left image, the crease is visible. The image on the upper right is the top SEM image, and it can be seen that the silver layer is uniformly dense. The image on the lower right is the cross-sectional SEM image, and it shows that the thickness of the metallized layer formed was about $7.68 \mu \mathrm{m}$, which met the requirements of antenna radiation.

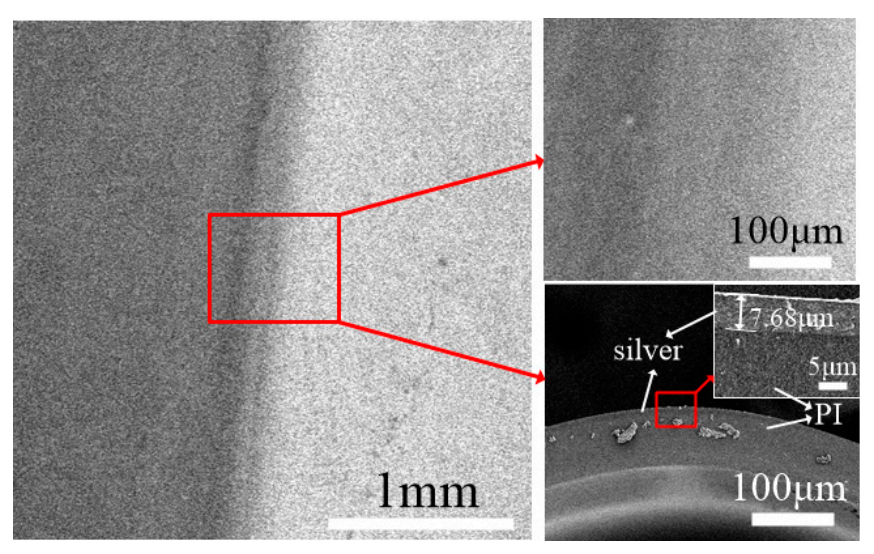

Figure 13. Top and cross-sectional SEM images of the film (folded).

As listed in the Table 4, the resistivity values of the films were also measured under the flat and different times of folding, which changed little, and prove that the properties of the thin films fabricated by in situ self-metallization technique are stable under certain deformation.

Table 4. Resistivity values of the films under the flat and different times of folding.

\begin{tabular}{cc}
\hline Times & Resistivity Values $\left(\mathbf{1 0}^{-\mathbf{5}} \boldsymbol{\Omega} \cdot \mathbf{c m}\right)$ \\
\hline 0 (Flat) & 4.85 \\
1 & 4.85 \\
10 & 4.85 \\
30 & 4.86 \\
50 & 4.87 \\
\hline
\end{tabular}


Screen printing $[1,2,6]$ and inkjet printing $[5,7,33,34]$ are the main techniques for applying antennas on PI films, and comparisons of fabrication methods of flexible antennas on polyimide substrates are listed in the Table 5 . It can be seen from the table that whether the antenna fabricated by in situ self-metallization was flat, bent, or folded, the changes of the resonant frequency and bandwidth were relatively small, and the change of printed antennas were bigger than the proposed antenna, which had no folding test. Meanwhile, the measured gain of the proposed antenna was excellent. This shows the superiority of the in situ self-metallization technology and broadens the application scene of flexible antennas.

Table 5. Comparison of different fabrication methods of flexible antennas on polyimide substrates.

\begin{tabular}{|c|c|c|c|c|c|c|c|c|c|c|}
\hline \multirow{2}{*}{ Ref. } & \multirow{2}{*}{ Methods } & \multirow{2}{*}{$\begin{array}{c}\text { Total Size } \\
\mathbf{L} \times \mathbf{W} \times \mathrm{H} \mathrm{mm}^{3}\end{array}$} & \multirow{2}{*}{ Gain (dBi) } & \multirow{2}{*}{ Rad. $^{1}$} & \multicolumn{3}{|c|}{ Resonant Frequency (GHz) } & \multicolumn{3}{|c|}{ Bandwidth (GHz) } \\
\hline & & & & & Flat & Bend & Fold & Flat & Bend & Fold \\
\hline [1] & Screen-printed & $55 \times 40 \times 0.125$ & 5.9 & Omn. $^{2}$ & 4.36 & $4.345(20)^{3}$ & $\mathrm{NA}^{4}$ & $1.77-6.95$ & $1.83-6.94(20)$ & NA \\
\hline [2] & Screen-printed & $20 \times 28 \times 0.025$ & 2.81 & Omn. & 4.85 & $4.84(25)$ & NA & $3.44-6.26$ & $3.33-6.36(25)$ & NA \\
\hline [5] & Inkjet-printed & $40 \times 30 \times 0.0508$ & 4.8 & Omn. & 2.5 & $2.35(27)$ & NA & $2.25-2.75$ & $2.23-2.65(27)$ & NA \\
\hline [6] & Screen-printed & $47 \times 33 \times 0.0508$ & 5.3 & Omn. & 3.75 & $3.80(10)$ & NA & $2.2-14.3$ & $2.15-14.35(10)$ & NA \\
\hline [7] & Inkjet-printed & $31 \times 34 \times 0.0508$ & 1.68 & Omn. & 2.46 & $2.4(7)$ & NA & $2.136-2.784$ & $2.12-2.88(7)$ & NA \\
\hline [33] & Inkjet-printed & $70 \times 70 \times 0.11$ & 2.1 & Omn. & 1.2 & $1.23(78)$ & NA & $0.87-1.52$ & $0.86-1.5(78)$ & NA \\
\hline [34] & Inkjet-printed & $30 \times 26 \times 0.125$ & 4.5 & Uni. ${ }^{5}$ & 4.83 & $4.84(50)$ & NA & $4.79-5.04$ & $4.76-5.08(50)$ & NA \\
\hline proposed & In the work & $40.6 \times 50 \times 0.075$ & 2.98 & Omn. & 2.28 & $2.29(40)$ & 2.32 & $2.06-2.74$ & $2.08-2.78(40)$ & $2.05-2.75$ \\
\hline
\end{tabular}

${ }^{1}$ Rad. $=$ radiation pattern; ${ }^{2}$ Omn. $=$ omnidirectional $;{ }^{3}$ antenna bending radius $;{ }^{4} \mathrm{NA}=$ not available $;{ }^{5}$ Uni. $=$ unidirectional.

A comparison of flexible antennas fabricated on different substrates is listed in the Table 6, including polydimethylsiloxane (PDMS), Rogers 5880, polytetrafluoroethene (PTFE), felt fabric, and liquid crystal polymer (LCP). It can be found from the table that the measured gain of the flexible antenna proposed in the work is excellent, and the flat, bending, and folding test results were relatively well maintained. In addition, a fatigue test was also performed in this study, which has not been reported in previous work.

Table 6. Comparison of flexible antennas fabricated on different substrates.

\begin{tabular}{|c|c|c|c|c|c|c|c|c|c|c|}
\hline \multirow{2}{*}{ Ref. } & \multirow{2}{*}{ Substrate } & \multirow{2}{*}{$\begin{array}{c}\text { Total Size } \\
\mathbf{L} \times \mathbf{W} \times \mathrm{H} \mathrm{mm}^{3}\end{array}$} & \multirow{2}{*}{ Gain (dBi) } & \multirow{2}{*}{ Rad. $^{1}$} & \multicolumn{3}{|c|}{ Resonant Frequency (GHz) } & \multicolumn{3}{|c|}{ Bandwidth (GHz) } \\
\hline & & & & & Flat & Bend & Fold & Flat & Bend & Fold \\
\hline [35] & SU-8/PDMS & $20 \times 46.4 \times 0.55$ & 2.17 & Uni. $^{2}$ & 6.30 & $6.25(50)^{3}$ & $\mathrm{NA}^{4}$ & $6.2-6.4$ & $6.15-6.38(50)$ & NA \\
\hline [36] & Rogers 5880 & $52 \times 43 \times 0.127$ & 3.57 & Uni. & 1.574 & $1.567(40)$ & NA & $1.56-1.59$ & $1.54-1.58(40)$ & NA \\
\hline [37] & Felt fabric & $26 \times 47 \times 1$ & 1.6 & Omn. 5 & 2.39 & $2.42(25)$ & NA & $2.16-2.63$ & $2.14-2.65(15)$ & NA \\
\hline [38] & PTFE & $25 \times 50 \times 0.127$ & NA & Omn. & 3.50 & $3.90(80)$ & NA & $3.4-3.6$ & $3.6-3.9(50)$ & NA \\
\hline [39] & LCP & $20 \times 32 \times 0.1$ & 0.31 & Omn. & 2.63 & $2.3(50)$ & NA & $2.38-2.79$ & $2.2-2.53(50)$ & NA \\
\hline proposed & PI & $40.6 \times 50 \times 0.075$ & 2.98 & Omn. & 2.28 & $2.29(40)$ & 2.32 & $2.06-2.74$ & $2.08-2.78(40)$ & $2.05-2.75$ \\
\hline
\end{tabular}

${ }^{1}$ Rad. $=$ radiation pattern; ${ }^{2}$ Uni. $=$ unidirectional; ${ }^{3}$ antenna bending radius; ${ }^{4} \mathrm{NA}=$ not available; ${ }^{5}$ Omn. $=$ omnidirectional.

\section{Conclusions}

The flexible monopole antenna was fabricated on $0.075 \mathrm{~mm}$ PI films by in situ selfmetallization. The technology does not require expensive equipment, and the metal on the surface does not peel easily. The antenna is fed by CPW with a simple structure and stable performances. When the flexible monopole antenna was under the flat state, the measured results showed that the resonance frequency was $2.28 \mathrm{GHz}$, the $-10 \mathrm{~dB}$ bandwidth was 2.06-2.74 GHz, and the relative bandwidth was $28.33 \%$. The performances of the antenna meet the necessary requirements after bending and folding. A fatigue test was carried out to illustrate that the prepared film has high mechanical flexibility, which expands the application field of antenna.

Author Contributions: Conceptualization, Z.W. and D.C.; methodology, Z.W.; software, D.C.; validation, D.C., Z.W. and H.Q.; formal analysis, D.C.; investigation, Z.W.; resources, Z.W.; data curation, D.C.; Writing-Original draft preparation, D.C.; Writing-Review and editing, Z.W.; visualization, Z.W.; supervision, Z.W.; project administration, Z.W.; funding acquisition, Z.W. All authors have read and agreed to the published version of the manuscript. 
Funding: This research was funded by the Nantong Science and technology project (JC2019112), supported by Shanghai Key Laboratory of Multidimensional Information Processing, East China Normal University (2020MIP003) and supported by the Fundamental Research Funds for the Central Universities. (Corresponding author: Zhiliang Wang).

Conflicts of Interest: The authors declare no conflict of interest.

\section{References}

1. Abutarboush, H.F.; Li, W.W.; Shamim, A. Flexible-Screen-Printed Antenna with Enhanced Bandwidth by Employing Defected Ground Structure. IEEE Antennas Wirel. Propag. Lett. 2020, 19, 1803-1807.

2. Faisal, F.; Amin, Y.; Cho, Y.; Yoo, H. Compact and Flexible Novel Wideband Flower-Shaped CPW-Fed Antennas for High Data Wireless Applications. IEEE Trans. Antennas Propag. 2019, 67, 4184-4188. [CrossRef]

3. Jilani, S.F.; Munoz, M.O.; Abbasi, Q.H.; Alomainy, A. Millimeter-Wave Liquid Crystal Polymer Based Conformal Antenna Array for 5G Applications. IEEE Antennas Wirel. Propag. Lett. 2019, 18, 84-88. [CrossRef]

4. Lin, X.Y.; Seet, B.C.; Joseph, F.; Li, E. Flexible Fractal Electromagnetic Bandgap for Millimeter-Wave Wearable Antennas. IEEE Antennas Wirel. Propag. Lett. 2018, 17, 1281-1285. [CrossRef]

5. Raad, H.R.; Abbosh, A.I.; AI-Rizzo, H.M. Flexible and Compact AMC Based Antenna for Telemedicine Applications. IEEE Trans. Antennas Propag. 2013, 61, 524-531. [CrossRef]

6. Khaleel, H.R.; AI-Rizzo, H.M.; Rucker, D.G. A Compact Polyimide-Based UWB Antenna for Flexible Electronics. IEEE Antennas Wirel. Propag. Lett. 2012, 11, 564-567. [CrossRef]

7. Khaleel, H.K.; AI-Rizzo, H.M.; Abbosh, A.I. A Compact Dual Band Polyimide Based Antenna for Wearable and Flexible Telemedicine Devices. Prog. Electromagn. Res. C 2016, 63, 153-161.

8. Wu, J.; Wu, Z.X.; Tao, K.; Liu, C.; Yang, B.R.; Xie, X.; Lu, X. Rapid-response, reversible and flexible humidity sensing platform using a hydrophobic and porous substrate. J. Mater. Chem. B 2019, 7, 2063-2073. [CrossRef]

9. Cheng, X.Y.; Wu, J.Y.; Blank, R.; Senior, D.E.; Yoon, Y.K. An Omnidirectional Wrappable Compact Patch Antenna for Wireless Endoscope Applications. IEEE Antennas Wirel. Propag. Lett. 2012, 11, 1667-1670. [CrossRef]

10. Guo, X.H.; Huang, Y.; Xie, Z.C. Flexible and Wearable 2.45 GHz CPW-Fed Antenna Using Inkjet-Printing of Silver Nanoparticles on Pet Substrate. Microw. Opt. Technol. Lett. 2017, 59, 204-208. [CrossRef]

11. Liu, S.Y.; Moncion, C.; Zhang, J.W.; Balachandar, L.; Kwaku, D.; Riera, J.J.; Volakis, J.L.; Chae, J. A fully-passive flexible wireless neural recorder for the acquisition of neuropotentials from a rat model. ACS Sens. 2019, 4, 3175-3185. [CrossRef] [PubMed]

12. Rodrigues, F.; Ribeiro, J.F.; Anacleto, P.; Fouchard, A.; David, O.; Sarro, L.; Mendes, P. Fabrication and characterization of polyimide-based, "smooth" titanium nitride microelectrode arrays for neural stimulation and recording. J. Neural. Eng. 2019, 24, 3067-3072. [CrossRef] [PubMed]

13. Pan, T.S.; Dai, L.L.; Chen, S.H.; Yan, Z.C.; Lin, Y. Low-Impedance Flexible Archimedean -Equiangular Spiral Antenna. IEEE Antennas. Wirel. Propag. Lett. 2019, 18, 1789-1793. [CrossRef]

14. Chauraya, A.; Whttow, W.G.; Vardaxoglou, J.C. Inkjet Printed Dipole Antennas on Textiles for Wearable Communications. J. IET Microw. Antennas Propag. 2013, 7, 760-767. [CrossRef]

15. Guo, X.H.; Huang, Y.; Pan, W.D. Flexible and Deformable Monopole Antenna Based on Silver Nanoparticles for Wearable Electronics. J. Nanosci. Nanotechnol. Lett. 2017, 9, 1632-1638. [CrossRef]

16. Wu, R.X.; Fang, X.M. A Novel Primary-Embedded On-Chip Transformer for 6-kV-Isolation High-Efficiency DC-DC Conversion. IEEE Electron Device Lett. 2019, 40, 586-588. [CrossRef]

17. Sirringhaus, H.; Kawase, T.; Friend, R.H.; Shimoda, T.; Inbasekaran, M.; Wu, W.; Woo, E.P. High-Resolution Inkjet Printing of All-Polymer Transistor Circuits. Science 2000, 290, 2123-2126. [CrossRef]

18. Chen, B.L.; Kruse, M.; Xu, B.; Tutika, R.; Zheng, W.; Bartlett, M.D.; Wu, Y.; Claussen, J.C. Flexible thermoelectric generators with inkjet printed bismuth telluride nanowires and liquid metal contacts. Nanoscale 2019, 11, 5222. [CrossRef]

19. Srifi, M.N.; Podilchak, S.K.; Essaaidi, M. Compact Disc Monopole Antennas for Current and Future Ultrawideband (UWB) Applications. IEEE Trans. Antennas Propag. 2011, 59, 4470-4480. [CrossRef]

20. Nikolaou, S.; Ponchak, G.E.; Papapolymerou, J. Conformal double exponentially tapered slot antenna (DETSA) on LCP for UWB applications. IEEE Trans. Antennas Propag. 2011, 54, 1663-1669. [CrossRef]

21. Cheng, S.; Wu, Z.G.; Hallbjorner, P. Foldable and Stretchable Liquid Metal Planar Inverted Cone Antenna. IEEE Trans. Antennas Propag. 2009, 57, 3765-3771. [CrossRef]

22. Shaker, G.; Safavi-Naeini, S.; Sangary, N. Inkjet Printing of Ultrawideband (UWB) Antennas on Paper-Based Substrates. IEEE Trans. Antennas Propag. 2011, 10, 111-114. [CrossRef]

23. Khaleel, H.R. Design and fabrication of compact inkjet printed antennas for integration within flexible and wearable electronics. IEEE Trans. Antennas Propag. 2014, 4, 1722-1728. [CrossRef]

24. Wu, Z.P.; Wu, D.Z.; Qi, S.L.; Zhang, T.; Jin, R.G. Preparation of surface conductive and highly reflective silvered polyimide films by surface modification and in situ self-metallization technique. Thin Solid Film. 2005, 493, 179-184. [CrossRef]

25. Wu, Z.P.; Wu, D.Z.; Yang, W.T.; Jin, R.G. Preparation of highly reflective and conductive metallized polyimide films through surface modification, Processing, morphology and properties. J. Mater. Chem. 2006, 16, 310-316. [CrossRef] 
26. Sang, J.P.; Tae-Jun, K.; Juil, Y. Copper circuit patterning on polymer using selective surface modification and electroless plating. Appl. Surf. Sci. 2017, 396, 1678-1684.

27. Yan, W.; Yu, W.; Jin-ju, C. A facile process combined with inkjet printing, surface modification and electroless deposition to fabricate adhesion-enhanced copper patterns on flexible polymer substrates for functional flexible electronics. Electrochim. Acta 2016, 218, 24-31.

28. Yang, T.; Yu, Y.Z.; Zhu, L.S. Fabrication of silver interdigitated electrodes on polyimide films via surface modification and ion-exchange technique and its flexible humidity sensor application. Sens. Actuators B 2015, 208, 327-333. [CrossRef]

29. Al-Yasir, Y.A.; Alkhafaji, M.K.; Alhamadani, A.; Ojaroudi Parchin, N.; Elfergani, I.; Saleh, A.L.; Rodriguez, J.; Abd-Alhameed, R.A. A New and Compact Wide-Band Microstrip Filter-Antenna Design for 2.4 GHz ISM Band and 4G Applications. Electronics 2020, 9, 1084. [CrossRef]

30. Elfergani, I.; Iqbal, A.; Zebiri, C.; Basir, A.; Rodriguez, J.; Sajedin, M.; de Oliveira Pereira, A.; Mshwat, W.; Abd-Alhameed, R.; Ullah, S. Low-Profile and Closely Spaced Four-Element MIMO Antenna for Wireless Body Area Networks. Electronics 2020, 9, 258. [CrossRef]

31. Guan, C.-E.; Fujimoto, T. Design of a Wideband L-Shape Fed Microstrip Patch Antenna Backed by Conductor Plane for Medical Body Area Network. Electronics 2019, 9, 21. [CrossRef]

32. Li, Y.J.; Lu, Z.Y.; Yang, L.S. CPW-Fed Slot Antenna for Medical Wearable Applications. IEEE Access 2019, 7, 42107-42112. [CrossRef]

33. Ahmed, S.; Tahir, F.A.; Shamim, A.; Cheema, H.M. A Compact Kapton-Based Inkjet-Printed Multiband Antenna for Flexible Wireless Devices. IEEE Antennas Wirel. Propag. Lett. 2015, 14, 1802-1805. [CrossRef]

34. Li, W.T.; Hei, Y.Q.; Grubb, P.K.; Shi, X.W.; Chen, R.T. Inkjet Printing of Wideband Stacked Microstrip Patch Array Antenna on Ultrathin Flexible Substrates. IEEE Trans. Compon. Packag. Manuf. Technol. 2018, 8, 1695-1701. [CrossRef]

35. Lin, C.P.; Chang, C.H.; Cheng, Y.T. Development of a Flexible SU-8/PDMS-Based Antenna. IEEE Antennas Wirel. Propag. Lett. 2011, 10, 1108-1111.

36. Tang, M.C.; Zhou, B.; Ziolkowski, R.W. Flexible Uniplanar Electrically Small Directive Antenna Empowered by a Modified CPW-Feed. IEEE Antennas Wirel. Propag. Lett. 2016, 15, 914-917. [CrossRef]

37. Chaihongsa, W.; Phongcharoenpanich, C. Performance of Textile Antenna using Two Layers of Strip Line and Round-off Circular Patch. In Proceedings of the IEEE Conference on Antenna Measurements \& Applications(CAMA), Chiang Mai, Thailand, 30 November-2 December 2015; pp. 1-3.

38. Liu, H.W.; Zhu, S.S.; Wen, P.; Xiao, X.; Chen, W.Q.; Guan, X.H. Flexible CPW-Fed Fishtail-Shaped Antenna for Dual-Band Applications. IEEE Antennas Wirel. Propag. Lett. 2014, 13, 770-773.

39. Du, C.Z.; Li, X.D.; Zhong, S.S. Compact Liquid Crystal Polymer Based TriBand Flexible Antenna for WLAN/WiMAX/5G Applications. IEEE Access 2019. [CrossRef] 